\title{
El maestro en sus lenguajes, un artesano de su devenir. ¿Fantasías de una utopía?
}

\author{
Miguel Alberto González González ${ }^{1}$ \\ Universidad de Manizales (Colombia) \\ miguelg@umanizales.edu.co
}

Recepción: 13/03/2013

Evaluación: 31/05/2013

Aceptación: 28/06/2013

Artículo de Reflexión

DOI: http:/ / dx.doi.org / 10.9757 / Rhela. 21.10

\section{RESUMEN}

El presente texto, deviene de una investigación realizada en la universidad de Manizales, Colombia, titulada "Visión de filósofos y literatos sobre el devenir de la universidad contemporánea, reconfigurada durante los años 2008 y 2011", donde emergen de una serie de aspectos conflictivos que dieron pábulo a esta ocupación escrita, entre otras, la poca fortaleza académica, la poca innovación, la poca relación entre teoría y práctica, el descreimiento de los propios conocimientos y cierto desinterés del docente por su labor. Pero también, cierta esperanza, cierto devenir sin agonía como una suerte de victoria por conquistar, por parte del docente, abrieron paso a esta reflexión académica; un profesor que artesana su devenir y que aún puede creer en las fantasías de una utopía.

En unas épocas de descreimiento, de velación de lo propio para el latinoamericano, donde lo extraño nos seduce, no es raro que el profesor, al querer ser científico, filósofo u experto en un tema en particular, abandone su misión primera, ser un mediador de lo humano entre sujetos, de las producciones culturales, de las diversas culturas con sus deseos de conservación y los temores a la renovación.

Por lo tanto, el devenir del profesor en la educación vendría dado por una serie de circunstancias políticas, económicas, normativas, tecnológicas y sociales que no siempre se comprenden y que limitan, de cierta manera, el acto de enseñanza-aprendizaje, digamos que al no dársele una lectura adecuada a tales dificultades se podría poner en crisis la reserva moral de la humanidad como se le ha comprendido a la educación.

En tal circunstancia, para convocar unos tiempos diversos a los que por este primer decenio del siglo XXI atraviesa el docente, se requiere de un compromiso con el pensamiento, con la humanidad, mas no con una ideología en particular, con acciones que permitan debilitarse

1 Director Revista Plumilla Educativa Universidad de Manizales-Colombia. Docente e investigador Maestrías Universidad de Manizales. Docente en la Facultad de Ciencias Sociales de La Universidad de Manizales. PhD en Ciencias de la Educación Universidad Tecnológica de Pereira-Colombia y PhD en Conocimiento y cultura en América Latina, Ipecal, México. 
y ayudar a debilitar los muros que le impiden al maestro salir del acorralamiento, muros físicos, psicológicos, artificiales, naturales, políticos, lingüísticos y míticos.

Así las cosas, el devenir del profesor en la educación no está dado, no es un destino manifiesto, es una construcción, es un ejercicio

The teacher, a craftsman of his future. Fantasies of an utopia?

\section{ABSTRACT}

The present paper is the result of a research developed in the University of the University of Manizales-Colombia "Vision of philosophers and writers on occurring of the contemporary university, re-built during 2008 and 2010". Where a variety of difficult aspects gave the possibility to write this, among some of them the lack of academic strength, low of innovation, lack of relationship between practice and theory, lack of confidence in the own knowledge, and certain lack of interest of the teacher for his work, but also certain hope, true to occur without agony as a luck of victory for conquering on the part of the teacher they made way to this academic reflection; A teacher who craft his future and that he can still believe in the fantasies of an utopia.

In the era of unbelief in the same for latin americans, where the strange seduces us, it is not uncommon for the teacher wanting to be a scientist, philosopher or expert on a particular topic, to abandon its mission first, be a mediator between the cultural productions, as technologies or theories and the popular cultures

\section{O professor, um artesão de seu devenir. Fanta- sias de uma utopia?}

\section{RESUMO}

O presente pergaminho resulta de uma pesquisa realizada na universidade de Manizales, Colômbia, intitulada "Visão de filósofos e literatos sobre o devenir da universidade contemporânea, reconfigurada durante os anos 2008 e 2010". Uma série de aspectos conflitivos de autonomía que, como la vida, se conquista día a día. Ni más ni menos.

Palabras clave: Revista Historia de la Educación Latinoamericana, Profesor, provocado, destino, educación, dilema, prospectiva, potencial, cambio, muro, derrota, esperanza.

with its desire to conservation and the fears of the renewal.

Thus, the evolution of teacher in education would be given by a set of political, economic, technological and social circumstances that are not always understood and that limit, in some way, the Act of teaching-learning, say that to not giving him a reading adapted to such difficulties could be in crisis the moral world reserves as he is understood to education.

In this circumstance, to convey different times to those related to the first decade of the twentyfirst century that crosses the teacher; it requires a commitment with the thought, not with a particular ideology in order to weaken the walls that prevent the teacher get out of the rounding up, these walls are not only the physical order.

As well as, the evolution of the teacher in the education is not given, it is a construction, it is an exercise of autonomy that, as the life is conquest day to day.

Key Words: Journal of the history of the Latin American Education, teacher, destination, education, dilemma, foresight, potential, change, wall, defeat, hope.

deram suporte a esta ocupação escrita, entre outras a baixa fortaleza acadêmica, a baixa inovação, a baixa relação entre teoria e prática, a descrença dos próprios conhecimentos e certo desinteresse do docente por seu trabalho, porém também certa esperança, certo devenir sem agonia como um tipo de vitória por conquista por parte do docente abriram espaço a esta reflexão acadêmica; um professor que constrói seu devenir e que ainda pode crer nas fantasias de uma utopia. Em uma época de descrença do 
próprio latino-americano, em que o estranho nos seduz, não é raro que o professor, querendo ser científico, filósofo ou especialista em um tema em particular, abandone sua missão primeira, ser um mediador entre as produções culturais, como tecnologias ou teorias e as culturas populares com seus desejos de conservação e os temores de renovação.

Portanto, o devenir do professor na educação se daria por uma série de circunstâncias políticas, econômicas, normativas, tecnológicas e sociais que nem sempre se compreendem e que limitam, de certa maneira, o ato de ensino-aprendizagem, digamos que, ao não se fazer uma leitura adequada a tais dificuldades, poderia se colocar em crise a reserva moral da humanidade como se compreendeu a educação.
Em tal circunstância, para convocar tempos diferentes aos que atravessa o docente neste primeiro decênio do século XXI, se requer um compromisso com o pensamento, mas não com uma ideologia em particular, que permita debilitar e ajudar a debilitar os muros que impeçam ao professor sair do acuamento, muros que não somente são de ordem física.

Assim as coisas, o devenir do professor na educação não está dado, não é um destino manifesto, é uma construção, é um exercício de autonomia que, como a vida, se conquista dia a dia. Nem mais nem menos.

Palavras-chave: Revista História da Educação Latino-americana, Professor, provocado, destino, educação, dilema, prospectiva, potencial, mudança, muro, derrota, esperança.

\section{INTRODUCCIÓN}

Estas discusiones, glosas devenidas de un transito investigativo, puntualizan en el quehacer docente dentro de la educación y la posibilidad de provocar el destino, de artesanarlo, es decir, es una instigación para que el profesor se ocupe en trazar su destino y a no esperar a que los demás, la externalidad, le indiquen el paso a seguir, olvidándose así de su autonomía y de aquella misión que Sócrates o, tal vez, Platón le entregó a los filósofos "sacar al hombre de la caverna, liberarlo de sus sombras, de sus propios espantos, de sus propias taras". Si bien, un profesor no es un filósofo, no es un científico ni un purista de la lengua, sí debe saber que aún se le sigue depositando la responsabilidad de conducir a la sociedad desde su infancia primera hasta sus últimos días, es un guía que viaja por unas rutas del conocimiento, por unas rutas que no desborden ciertos acuerdos morales que no requieren largas escrituras para describirlos en códigos de ética, porque el sentido común lo intuye: no traspasar la suerte de las especies ni intervenir su futuro, cual dios judeocristiano, por nobles y loables que puedan ser dichos ideales.

La meditación viene dada de una investigación donde participaron filósofos y literatos de las universidades de Manizales, Caldas, Autónoma, Tecnológica de Pereira y Universidad de Florida en Estados Unidos, titulada 
"Visión de filósofos y literatos sobre el devenir de la universidad". En esta, cada pensador fue dando su versión de universidad, la existente y la por venir como en cierta añoranza no del pasado sino del futuro por construir, donde emergen ciertos deseos de humanidad que, pese a tantas sombras e incertidumbres, aun se depositan el sistema educativo en cabeza de los profesores.

Entre las muchas posibilidades de universidad, al profesor se le asignó un papel protagónico que no debe ni puede ser delegado que, en la mayoría de los casos, nos han sellado en el ejercicio docente como una derrota admitida, unos dilemas, unos anquilosamientos, una historia repetida, pero no admitida y, finalmente, unos legítimos anhelos de prospectiva que destierre tanto apocalipsis vendido por algunas religiones y poderes de turno.

\section{La derrota}

El hombre puede ser destruido, pero no derrotado.

Ernest Hemingway.

A no dudarlo, la caída del hombre se encuentra en las cosmogonías, donde siempre salieron airosos los dioses, claro, victorias pírricas, pero muy dramáticas para la humanidad, lo cual es verificable en muchos textos sagrados o en aquellos relatos menos ampulosos o pretensiosos de universalidad como los venidos de comunidades indígenas. El desalojo de Adán del paraíso, las plagas de Egipto, el diluvio universal, la condena de Prometeo por entregarles el fuego a los hombres o la epidemia de los hombres de Tenui en Yuruparí nos confirman que hemos sido prescritos para la caída, para la destrucción, pero no para la derrota, pues siempre, aún en las condiciones más infames, nos hemos sabido levantar, nos hemos sobrepuesto a los mismos dioses porque los demonios, más o menos, nos han consentido, más o menos han estado de nuestra parte.

Los aspectos que configuran a un docente contemporáneo y su destinación están en constante construcción, en un mundo sin aparente norte, y en el cual el sur no ha tomado posición, un mundo donde lo sólido, en palabras de Bauman "se está derritiendo para dar paso a lo informe, a lo líquido", las esperanzas parecen nubladas, sombreadas por la desgracia; por suerte, nada 
puede ser definitivo ni excluyente; si en algo aplica, podría decirse que, en esta disertación, el docente podrá demolerse, pero jamás derrotarse.

Dar una mirada al presente potencial en la educación contemporánea; en una época de cifras y siglas, en versión de Foucault, es una demanda intelectual en permanente ejecución de trayecto-deyecto-proyecto. Trayecto como espacio andado, deyecto como el regreso sobre el trayecto, el dar no la mirada sino el paso atrás, claro, ambos, trayecto-deyecto, categorías espaciales para luego pasar al proyecto que, como categoría temporal, nos entrega la ilusión de un porvenir, en este caso, menos apocalíptico; todo esto, sabiéndose que los cambios en la educación dependen de lo que los profesores hacen y piensan, algo tan simple y tan complejo a la vez. Una clásica afirmación anglosajona sentencia "What you want in state you must put in school", "Lo que quieras en el Estado debes ponerlo en la escuela". Premodernidad-modernidad-posmodernidad son categorías cronológicashistóricas-ahistóricas que requieren ser encaradas en sus agujeros negros, pero también en sus constelaciones iluminadas para que el maestro, al menos se dé cuenta, que si es objeto del Estado, no se conforme con mencionarlo ni lamentarse, ha de levantarse desde sus lenguajes para artesanar su devenir.

Las dificultades comunes en la educación del primer, segundo y tercer mundo se centran en lo problemático que ha sido enseñar el humanismo, puesto que los poderes económicos, políticos, religiosos, científicos y militares han radicalizado sus apuestas instrumentales y des-etizadas. Un profesor competente, logra enseñar cómo manejar máquinas o programas de computadoras, sin embargo tiene problemas en pro-mover personas integrales-universales-sentimentales porque las dinámicas de mercado siempre están vendiendo cosas que no logran ser desenmascaradas, están vendiendo futuros con el precio del presente, están vendiendo pobreza con el endeudamiento del presente, están vendiendo felicidad con las máscaras del dinero, en definitiva, están vendiendo miseria y eso debería saberlo el docente en destino provocado, intuido y no leído como un destino manifiesto o destino bíblico. 
Un profesor que es artesano de su devenir comprende su proceso cual expone Freire " "La educación como práctica de la libertad", pero, en términos generales, un profesor sin ilusiones de utopía, no le interesa la libertad propia ni mucho menos la de sus compañeros de aula, como nos lo hace ver Freire y el mismo Giroux, un profesor sin ilusiones de comprenderse como intelectual, es posible que sea un profesor sin compromiso social, sin humanismo.

Frente al humanismo, Foucault en su texto Saber y vedad advierte que "El humanismo finge resolver los problemas que no se puede plantear", ${ }^{3}$ deja en evidencia que la expresión humanismo por sí sola es inferior a la realidad que convoca. Así las cosas, y para no caer en idealismos ni en temerarias acusaciones, se libera de responsabilidad al profesor de la provincia, al héroe de aquellos lugares inhóspito, al que Ernesto Sabato dice que se quita el sombrero ante el maestro de la provincia que es relegado y, pese a ello, torna su enseñanza en verdadero arte, a ese lo considera un héroe.

El profesor que aquí ponemos en cuestión es al universitario, al citadino que, teniendo medios y posibilidades, actúa como si fuese un esclavo, como si no tuviese ilusiones de utopía, como si no pudiese ser un artesano de su devenir, docente que teniendo casi todo a su alcance se comporta como si no pudiera, se muestra ciego, desvalido e irresoluto, derretido o desprovisto de solidez y que, convertido en líquido, se desprende de su responsabilidad, escurriéndose por los intersticios para no asumirse; una especie de hombre sin norte, pero a quien tampoco le inquieta el sur o cualquiera de los otros puntos cardinales.

Esos otros puntos cardinales son para no caer en cierta derrota como nos muestra Foucault al decirnos que "Los intelectuales se han habituado a trabajar no en el universal, en el ejemplar, en eljusto-y-verdadero-para-todos, sino en sectores específicos, en puntos precisos en los que los situaban sus condiciones de trabajo, o sus condiciones de vida (la vivienda, el hospital, el manicomio, el laboratorio, la universidad, las relaciones familiares o sexuales)".${ }^{4}$ Esto es un dilema para el docente, para el docente que se

2 Freire, Paulo. Pedagogía del oprimido (Montevideo: Tierra Nueva., 1970), 13 Consulta 16 de agosto de 2012. http://www. libroselectrónicosgratis.com

3 Foucault, Michael, "Vérité et pouvoir", Revista L’Arc, N. 70 (1977): 16.

4 Foucault, Michael. Estrategias de poder (Barcelona: Paidós, 1999), 183. 
puede situar como intelectual bajo el contexto específico de la universidad, casi que soslayando los auténticos problemas de la humanidad.

\section{Los dilemas del docente}

Los síntomas no hablan de lo real, una fiebre podría estar ocultando una enfermedad terminal o un leve resfriado, un bajo rendimiento académico podría ser síntoma no de baja inteligencia sino de un problema social o emocional, por ello es que no se puede diagnosticar sobre las primera señales de los síntomas, hay que dar el paso atrás para encontrar la causa, por así decirlo, la fuente de los males; esto porque, en muchos casos, nos hemos habituado a ver los síntomas, a describirlos como si fuesen el problema en sí y con ello creemos estar dando cuenta de la realidad, mientras las causas se enquistan y, en tormentosas marejadas, van desvencijando el entorno que, en suma, es el hombre.

En cierto modo, nos dejamos obnubilar por cualquier síntoma, como un maquillaje, desconociendo que atrás de las capas de pintura se esconde la verdadera piel; hemos admitido que el cosmos se reduzca al cosmético, a peligroso camuflaje que mucho aporta a la mentira y poco hace por la solapada verdad. De ahí la importancia de una actitud crítica, de un pensamiento complejizado en los interrogantes y no bastado en las respuestas, algunas respuesta son una marejada de mentiras. La crítica supone una postura, en donde es requisito para el profesor cuidarse de no andar defendiendo supuestas verdades ajenas para convertirse en tribuno, es decir, continuar promulgando, repitiendo lo que otros anticiparon en sus formas de pensamiento o lo que el poder, con mucha habilidad, pone a circular ¿El maquillaje en la educación es un síntoma de qué?

El maquillaje es un mundo donde tras muchas capas se oculta el auténtico rostro, en el maquillaje no acaece lo que expone Ghiso ${ }^{5}$ que "Tanto los sujetos como el mundo son construidos en la interacción creativa, dialógica e intencionada"; esa construcción dialógica no implica un proceso sin sobresaltos, puesto que cualquier interacción creativa pone en tensión aquellos espacios y personas que se sienten afectados o amenazados; el

5 Ghiso, Alfredo. Potenciando la diversidad. Diálogo de saberes, una práctica hermenéutica colectiva (Medellín: Centro de Investigaciones Fundación Universitaria Luis Amigó 2000), 5. Consulta 15 de junio de 2011. http://bibliotecadigital.conevyt.org. $\mathrm{mx} /$ colecciones/documentos/potenciando_diversidad.pdf 
maquillaje, si bien hay creatividad, es una creatividad para la simulación, para ocultar las auténtica señales que envían los síntomas.

El maquillaje podría ser un estado de ánimo, por tanto, es importante establecer desde qué estado de ánimo se piensa, bien desde el pesimismo, desde la rabia, desde la zozobra, desde la intolerancia o desde la paciencia, de tal suerte que permita entender la intensidad del lenguaje y los mundos que convoca; hay lenguajes maquillados, lenguajes solapados, pero también existen lenguajes lúcidos, lenguajes brillantes que potencian sujetos y que aperturan sujetos; hay estados de ánimo geniales, radiantes, también los hay apocalípticos y destructores, pero asisten algunos estados de ánimo neutros o desinteresados de cualquier destino; a todos estos instantes de ánimo hay que hacerles auditoría, hay que identificarlos para saberse qué ocurre con los lenguajes venidos de dichos momentos anímicos y sus influencias en los procesos académicos, el no reconocerlos sienta la discusión por las gramáticas debilitadas para dar cuenta de los acontecimientos.

Varios dilemas se desprenden del acto docente, dilemas propios de la humanidad que no se pueden pasar por alto y tampoco se corrigen con el facilismo que nos propone el eclecticismo, es decir, tomar lo mejor de todos y seguir como si el mundo fuese un gran recipiente de mermeladas.

- Dilemas éticos, políticos, jurídicos, científicos, lógicos, filosóficos.

- Dilemas formativos, didácticos, pedagógicos, curriculares.

- Dilemas entre renovar, conservar y romper.

- Dilemas entre historizar, mitologizar y ficcionar.

- Dilemas entre altas culturas y culturas populares.

- Dilemas entre lo apolíneo y lo dionisiaco, entre razón, emoción, imaginación, seducción.

- Dilemas entre silenciar, hablar y ocultar,

- Dilemas entre prosa, poesía y lenguajes bináricos, maquínicos.

- Dilemas tecnológicos, informáticos, mediáticos.

- Dilemas entre el ser, el tener, el saber, el hacer, entre el ser algo y alguien.

- Dilemas entre luces, oscuridades, penumbras y umbrales.

Abordar estos dilemas, no porque deban resolverse, pero sí pensarse, exige gramáticas ampliadas, diccionarios más anchurosos que los propios de la 
cultura local, que los léxicos contextuales y que los lenguajes que imponen los poderes de turno.

Desde luego que un docente con gramáticas restringidas enseña pobremente, crea hombres menores, de pensamiento pequeño, con ideas bonsái, cuyo mundo de la vida no supera los presupuestos ideológicos de extraños mesías o no encuentra puntos de quiebre en los discursos de la institucionalidad, discursos que vende el orden; dichos sujetos convierten el aula en jaula, el salón de clases en cárcel de expresiones congeladas, acicaladas con artilugios lingüísticos. Por ello, recurrir a la poiesis o acto de creación, en el paso del no ser al ser, sin entrar aquí en discusiones con Parménides, es una estricta tarea para el superhombre, de aquel que está en condiciones de estrellar las ideas en las rocas hasta diseñar caminos con sus astillas, es necesario no dejarse obnubilar porque la poiesis es un fin en sí mismo y ya sabemos los riesgos que entrañan las teleologías, es decir, habría que trasladarla a medio, algo que mejor se comprende desde la praxis que va siendo fin y medio en una constante autoreformulación.

En tal sentido, apostarle a la plasticidad mental emerge como salida, en tanto pensar y hacer no pueda ser dicotómico, auscultando con mayor agresividad y creatividad desde la investigación los problemas epocales para llegar a otros ámbitos del saber sin repetir lo que ya se sabe, reconociendo que la revolución corre el riesgo de caer en la rutina, por repetirse en su propio agotamiento o muere en su hábito de conservación de aquello que ha instaurado. Renovación-seducción-cansancio, ciclo que debe superarse.

El docente no puede ser temerario, pretendiendo echar tierra a lo vivido, hacer de lo existente tierra arrasada al querer construir nuevas aventuras de la nada. Aquellas decisiones humanas que no dieron cuenta del pasado e ignoraron, en franca conciencia, el mundo recorrido, terminaron por dar propuestas más nefastas que el mismo problema. Peor el remedio que la enfermedad; recordemos algunas revoluciones políticas del siglo XX.

Siendo así, el profesor debe tomarse su tiempo para no caer en esnobismos o movimientos de moda, sabiéndose que, en muchas ocasiones, la moda es tan efímera como retrechera, por ello, al pasar de los días, pocos la extrañan. Al maestro le viene bien pensar despacio, dejar sedimentar ciertos torbellinos que solo sirven para ocultar el gran vendaval; el pensar 
despacio no implica hacerse el de la vista gorda o tornarse duro de oído, pensar despacio es darle tiempo al proceso biológico, es darle tiempo a las ideas para que circulen y se reconfiguren. Pensar despacio es saber que si algo es pensable, no quiere decir que sea deseable o moralmente aceptable.

¿El futuro puede ser decretado?, ¿manejado por normas? Las respuestas son diversas, pero se coincide que la norma no es el futuro, la letra lo intuye, sin embargo, no lo convoca; solo es el hombre con sus acciones que opta por aceptar u oponerse a lo decretado. Solo el ser humano, esperemos que no las máquinas, es quien busca tornar en realidad los sueños, en desterrar ciertas rutinas lingüísticas en la idea de hacer cosas con palabras, según previno Austin. Nada más sencillo, pero más complejo a la vez, que lenguaje, acción e ilusión. La triada lenguaje-acción-fantasía es una constante en el ser humano que empieza a reconocer el mundo desde la escuela, fantasía que se puede ir perdiendo con el tiempo o cuando peor con la intervención de la educación que, a veces, en lugar de enseñar a pensar, se dedica a fabricar seres humanos y ya sabemos que las fabricaciones de hombres terminan pareciéndose a Frankenstein.

\section{Los anquilosamientos}

En cierta manera, muchos docentes se habitúan a lo dado, se fosilizan en los cargos, se anquilosan en sus discursos, su pensamiento sufre artrosis o enfermedades similares que lo inmovilizan, por lo cual, sus lenguajes pasan a ser mecánicos y, claro, artríticos, quizá, hasta raquíticos.

- En el más de los casos se tiene a un educador acorralado por su forma circular y, a veces, poco efectiva de anticiparse a los tiempos; se precisa de cierto equilibrio para no caer en lo que Bauman nos menciona "Ser moderno significa estar eternamente un paso delante de uno mismo, en estado de constante transgresión". 6 Ser moderno es no detenerse, pero ir en calma. El educador ha de percatarse que cierta lentitud le viene bien como forma de oponerse a los modernos relojes de las economías.

- Llega a ser sucursal del pensamiento extranjero. A esto nos dice Goethe "Estudiando los apuntes de clase, os dareís mejor cuenta

6 Bauman, Zygmunt, Modernidad líquida (Buenos Aires: Fondo Cultura Económica, 2006), 34. 
que el profesor no dice nada que no se halle ya en un libro". ${ }^{7} \mathrm{Y}$ todo indica, no se deduce lo contrario, que los libros mencionados por Goethe no son los que el docente escribe, si es que escribe.

- Vivir a la zaga de los avances tecnológicos. Demonizarlos por una resistencia construida entre tradición y renovación, entre civilización y barbarie.

- Acogerse y permitir que él, junto a los estudiantes, acuda a la ley del mínimo esfuerzo.

- En algunos casos se anquilosa en discursos marxistas, imperialistas o progresistas que, en su mayoría, podrían ser tecnologías del discurso, burocracias del lenguaje.

- En términos generales, el catedrático es un profesional poco exitoso, los mejores están en la empresa privada.

- A veces le disgustan los dogmas y los paradigmas, pero le agrada imponerlos.

- Muchos docentes se dejan convencer de teorías globales o universales. A esto Zuleta nos advierte "Pero más frecuentemente aprendemos, tarde o temprano, a fuerza de duelos y de decepciones que no se debe tener confianza en ninguna teoría demasiado global". ${ }^{8}$

- Se matricula como museo del conocimiento y por eso llega tarde a la creación del saber.

- Tiene preguntas cadáver, cuyas respuestas son cementerios, osarios, preguntas momias cuyas respuestas están en los museos, es decir, todo un componente de preguntas con respuestas en las bibliotecas, en las enciclopedias universales.

- Prepara a los estudiantes para un mundo que ya pasó o para un mundo que devendrá ¿Y del presente que sabrá?

- La violencia, la guerra, como panorama de discusión, no emerge en el aula de manera organizada, tal vez, desconociendo a Gadamer cuando nos dice "Por primera vez se ha creado un arsenal de armas cuyo empleo ya no promete la victorial de alguien, sino que 
significará el suicidio colectivo de la civilización humana". ${ }^{9}$ Frente a esto ¿será ético que un docente se silencie?

- Salvo unas excepciones, es como dicen los críticos de los mormones, ni aprende ni olvida.

El docente ha contribuido a formar empresarios, industriales, arquitectos, administradores de empresas y otras endemias de control, eficientes y hasta inhumanos, por tanto, seres poco pensantes; exitosos, mas no críticos y liberadores; célebres, pero poco respetuosos del ambiente, de la vida y de los seres humanos. A muy pocos se le ocurre que es necesario ser felices, los demás no saben de felicidad, ni la buscan. De este panorama vale la pena recordar en el libro Frankenstein cuando Meirieu argumenta que "educar es, pues, introducir a un universo cultural, un universo en el que los hombres han conseguido amansar hasta cierto punto la pasión y la muerte, la angustia ante el infinito, el terror ante las propias obras, la terrible necesidad y la inmensa dificultad de vivir juntos" ${ }^{10}$

La sentencia es luminosa, pero qué sucede con el terror, con el miedo a la oscuridad o con el pavor a las luces que ahuyentan otras luces, ahora ¿qué se enseña desde el miedo? Puesto que muchos docentes ni siquiera han logrado amansar el miedo a lo desconocido; tal vez, desde el miedo lo que se fabrica es la sociedad del miedo, la sociedad del riesgo, la sociedad de la sospecha o la sociedad del susto y, quizá, por eso es que los poderes hacen de la humanidad lo que bien se les ocurra.

No es desconocer que el e-learning se ha convertido en una realidad académica cuyos horizontes se mueven en paradojas, en un caso, los seguidores de las Tics no dudan de las bondades, en tanto, que en otro lugar se encuentran los escépticos que se oponen por los miedos que suscitan ya no las máquinas sirviendo al hombre para facilitar aquellos grandes esfuerzos físicos, sino los hombres sirviendo a las máquinas, ya no se bastarían con suplantar fuerza física si no que vendrían a constituirse en una suerte de ciberconocimiento.

9 Gadamer, Hans-Georg, La herencia de Europa (Barcelona: Ediciones península, 1990), 22.

10 Meirieu, Philippe, Frankenstein educador (Barcelona: Leartes Ediciones, 1998), 25. 
De alguna manera, se entendería el papel del docente no de oponerse a la educación virtual por fruición, nostalgia o por simular odio sino por razones vitales, quizá de supervivencia. Su rol adquiere potencia cuando en acción de pensamiento activo logra fracturar las tecnologías burocráticas de la enseñanza, las tecnologías de los lenguajes; de lo contrario nos pasará lo mismo que con el capitalismo-salvaje o la globalización-bárbara que por no identificarla en su momento, solo nos podría quedar el lamento y la opinión ácida que en nada afecta el desarrollo del monstruo. No es de olvidar que lo virtual es la continuidad de las lógicas del capital por otros medios, pero con los mismos fines: someter e imponer ¿Es eso un cambio de época? Y si lo es, ¿qué tipo de cambio es ese?

Destaca Zemelman que "Vivimos hoy un cambio de época cuyas transformaciones y rupturas nos enfrentan a la necesidad de construir nuevas categorías para abordar los fenómenos, pero sin desconocer los conocimientos acumulados, muchos de ellos durante largos períodos"; ${ }^{11}$ las nuevas categorías no solo son del ámbito del discurso sino de la acción, de la experiencia e interacción con las realidades epocales, con los problemas de época.

¿El docente sabrá cuál es el ámbito construido de sus discursos? En ocasiones, sus discursos no son propios, son venidos del afuera y, por tanto, no logra intuir las columnas que sustentan su acto enseñante, podría aparecer un problema de territorio que los tecnócratas aprovecharían. ¿Cuál tiempo convocan sus silencios? La deuda de la modernidad es que no sabemos leer los silencios, nos convertimos en una sociedad del ruido donde los silencios no se leyeron con bastante inteligencia por caer en la tentación del vórtice de las palabras. ¿Cuáles acontecimientos permitirán una mejora del hombre sin deprimir el universo? La respuesta no aparece en folletines, hay que elaborarla, puesto que una respuesta venida de las éticas es un deber ser, pero la realidad nos viene atropellando con cierta demencia humana rejuvenecida, ni siquiera demencia senil, es una demencia llena de vitalidad en la destrucción. Falta un darse al otro y ese es el acto docente que no se puede dejar perder por la irrupción del e-learning y todas las tecnologías que más de la formación parecen de la fabricación, de la industrialización del conocimiento.

11 Zemelman, Hugo, Los horizontes de la razón III. El orden del movimiento (Barcelona: Anthropos, 2011), 15. 
Mèlich insiste en que educar es estar inclinado al otro, darse al otro, sin esperar nada a cambio. Entendido así, que en ese otro estoy yo, el maestro que no deja morir la palabra, que comprenda la alteridad como fundamento de su enseñar, que dé testimonio de sí y del otro, para pasar a ser un acontecimiento que rompe la linealidad de los cronómetros.

\section{Ahondar en la historia}

El porvenir está en manos de los maestros de escuela

Víctor Hugo

Pese a lo añejo del aforismo del autor de Los miserables, su vigencia es esperanzadora, si es que los docentes no son reemplazados por ordenadores y software con mayor paciencia que el mismo profesor. El célebre novelista japonés Yukio Mishima escribió: "Me di cuenta de que para nacer tan solo una flor eran necesarios, a la vez, la historia y el espíritu humanos actuando conjuntamente", y se agregaría que para no romper esa secuencia biológica factual, al profesor le asalta una enorme carga para que el hombre no intervenga en la destrucción de la flor ni del espíritu humano.

Al maestro le corresponde entender que las grandes verdades han determinado posiciones fascistas, ortodoxas, xenofóbicas y excluyentes aún dentro de la ciencia. Tiene que revaluar el concepto de verdad que aún se maneja, puesto que la búsqueda generosa de la verdad, la elección autónoma de métodos y temas de investigación, el apego por la ciencia sensata y el respeto por el medio ambiente, son funciones de un educador.

El profesor requiere fomentar el diálogo de saberes, recordar que los seres humanos emergimos de la vida y somos vida. Ayudar a reencantar el mundo por medio de la palabra, de la construcción de imaginarios que representen nuevas relaciones, otros valores, en el sentido positivo. El docente convocado deberá enseñar a vivir, a no abrigar angustia por el futuro, a gozar de la libertad, a disfrutar del cosmos y a respetar la vida en todas sus formas. Descubrir de nuevo, aunque suene romántico e idealista, que los hombres pasan pero el hombre es eterno.

Como no podemos cambiar el pasado -ni siquiera dios, de existir, puede hacerlo-, nos concierne mirar el futuro sin borrar el presente, tejer algo 
diferente, para evitar fiascos es condición sine quanon no improvisar sino acudir al saber construido, analizarlo y a partir de esto llamar el tiempo en perfecta conciencia de ejecutarlo, sin demoras bíblicas, ni premuras militares $\mathrm{o}$ ardides políticas, es decir, en franca acometida y sin dobleces; es posible que aquellos países que acuden a golpes militares tienen mucho afán.

El Apocalipsis está en deuda, no se ha ejecutado y, pese a sus anuncios vengativos, los hombres seguimos en la brega, prestos a protegernos de despilfarros agoreros. Por suerte, cuando las luces desaparecen o son apagadas aparece un maestro con un pensar emergente, con un pensar desde lo no dado que posibilita la construcción de horizontes; si es de alertarnos para no confundir un pensar emergente con un pensar mesiánico.

Los filósofos no siempre la pasan mejor, así hagan de profesores, con un tono sarcástico nos dice Enrique Quintero que "En el lejano país de Quiensabedonde había una especie de pájaros de canto estridente, llamados filósofos. Con sus graznidos hacían desapacible la vida en el lozano reino del príncipe" ${ }^{12}$ En su texto sugiere que estos pensadores quisieron seguir viviendo en las nubes por no arriesgar sus vidas bajando a la raíz, o sea, a la tierra, tal cual ocurrió con el primer pájaro filósofo, llámese Sócrates o Parménides, y como puede ocurrir con un profesor sin compromiso que se fuga a las nubes para no untarse de realidad.

\section{El futuro se decanta, el futuro llama ilusiones de utopía}

Estamos siempre inclinados a creer en aquello que deseamos.

Demóstenes

Si los deseos se vuelven creencias, entonces, muchas de nuestras inclinaciones deberían ser revisadas antes de volverlas creencias. El docente deberá apostarle al arte, patrocinándolo para enfrentar el tiempo libre como opción de vida. Ha de entender que la carencia de patria con que el mundo moderno amenaza al ser humano inspira la búsqueda de un mundo sin fronteras, sin himnos y sin banderas. Los maestros pensarán en formar hombres no para el trabajo sino para la estética, tratando de estar libre de cualquier dogma religioso, político, económico o social para

12 Quintero Valencia, Enrique, Cuentos de un Máximo Gris (Manizales: Editorial Manigraf, 1998), 75. 
movilizar creatividad en el conocimiento; fortaleciendo la democracia, no solo vista en movimiento sociopolítico sino transmutada en un estilo de vida. El excedente de la democracia es aceptar la impredecibilidad humana, la zozobra de vivir con otros, y responder por sí mismos; pero la realidad, menos preocupada por estos detalles, nos hace ver que, en la práctica, la democracia es indómita y, un tanto, socarrona.

El maestro pensará en forjar una comunidad académica con más voz y preponderancia en el concierto social, entendiendo a Santos cuando en su texto de La idea de universidad a la universidad de las ideas, destaca que es cada vez más importante suministrar a los estudiantes una formación cultural sólida y amplia, con marcos teóricos y analíticos generales, con una visión global del mundo de tal manera que pueda desarrollar un espíritu crítico y creativo, disponible para la innovación, con ambición personal y una actitud positiva frente al trabajo arduo y en equipo. Es posible que, el docente instrumentalista sea instrumento y gestará los hombres que quiere el poder, seres sin decisión y sumisos a los intereses dominantes del momento, debiendo saber que la acumulación de capital monetario es imposible sin el empobrecimiento de otros; eso al menos, han indicado las lógicas económicas conocidas.

El profesor ha de escribir su propia historia, narrando la realidad que le gusta, no la impuesta y que no le agrada. A esto nos obliga a reflexionar el filósofo Silvio Sánchez Fajardo en su libro Diálogos imperfectos, al exponer que la historia no es la narración de lo que ha ocurrido, la historia es lo que nos ha ocurrido y por eso hay que volver por las rutas de la memoria, de eso que hicimos para que nadie se olvide, puesto que la memoria es el tiempo atrapado. En virtud de lo dicho, se requiere instaurar comunidades de vida, de conocimiento y de pensamiento que contrarresten los patrones hegemónicos capitalistas-políticos-religiosos-científicos-educativos del momento. Formar conciencia en fortalecer las categorías de articulaciónorganización-complejidad-solidaridad-síntesis que permitan interpretar las fuerzas antagónicas, con menos violencias discursivas. Ha de entender que la Internet será decisiva, hará mucho más por la democratización de la información que la misma academia. A la educación le tocará romper los roles de profesor-estudiante, hoy practicados, y que tanto daño le han hecho a la formación; en ese sentido, el maestro tendrá mayores fuentes de 
desagrado para intervenir. Esto va en concordancia con Habermas, quien reveló que "el hombre necesita motivos de desagrado para poder actuar, de lo contrario se conforma". Visto así, el profesor tendrá bastante trabajo. Para dar una correcta lectura a la realidad se requiere el uso adecuado de la ciencia, con la promoción de la investigación sin métodos atosigantes, con la participación de la metáfora, el mito y el arte para que los docentes libres de doctrinas y en constante preparación, se encuentren con unos estudiantes sedientos de sabiduría, dispuestos a seguir haciendo preguntas hasta el fin de sus días.

Es pertinente entender a Foucault cuando agrega que la tarea de decir la verdad es un trabajo sin fin: respetarla en su complejidad es una obligación de la que no puede zafarse ningún poder, salvo imponiendo el servicio de la servidumbre.

\section{CONCLUSIÓN}

Sabemos que las cortinas de humo no dejan visualizar, dificultan distinguir, no admiten traslucir, son tan peligrosas como las máscaras. Es ineludible aprender a buscar lo no dicho en el discurso, lo reprimido, el inconsciente del sistema. También es claro que el análisis del presente y del pasado, expone Santos, por más profundo y documentado que sea, solo suministra un horizonte de posibilidades, un abanico de futuros posibles. De esto se desprende que el pasado se recupera si logra escribirse y que el futuro se convoca si logra ser intuido; sin duda, la conversión de uno de ellos en realidad será todo un esfuerzo de desgarramientos.

Al profesor le compete explorar opciones políticas diferentes a la democracia, para que no surja la dictadura de la democracia. Ha de resolver la pusilanimidad que se le fustiga, su inflexibilidad, la falta de compromiso histórico, la delegación de su misión profesoral y la continua queja. Tiene que evolucionar su razón vital histórica para que no sea estática, anquilosante y en el peor de los casos en retroceso, adecuando los discursos para que no parezcan de otra época y cuyo mundo teórico-práctico corresponda al de los estudiantes, al de una época de sentido; aprender a articular el saber, interesarse por las historias de vida de los "alumnos" y no convertirse en pequeño dictador de aula. 
Nos pregunta Guarín “QQuién tiene la autoridad en el conocimiento? Políticamente es una pregunta por la gobernabilidad ¿Quién debe gobernar el saber? Paradójicamente, responder a ella es incurrir en autoritarismo" ${ }^{13} \mathrm{El}$ autoritarismo que teme Germán es el dogmatismo y los paradigmas que se han venido al desprestigio, pero tal vez, para confluir con Guarín podríamos decirle que el conocimiento como construcción no siempre obedece a las lógicas del poder político, aunque en sí sea un poder, tenga autoridad en sí por definirse conocimiento, cuando deje de serlo, también dejará de ser conocimiento válido para esa época y para ese grupo social; entonces, el maestro más que ocuparse por la gobernabilidad del conocimiento debería ocuparse por los estatutos, del por qué ese conocimiento sí es conocimiento válido o siquiera aceptable en el entorno donde se encuentran tanto profesor como estudiante.

El maestro que aborde la problemática del delito y sus variantes, la trata de personas, el consumo de estupefacientes, los modos de celebrar las euforias deportivas y que insista en el debilitamiento de lenguajes machistas y racistas no será egoísta, ni mostrará desinterés por un presente en acometida, enriqueciendo los estados de prognosis, es un docente con sentido político.

Nos insiste Freire que "El acto de educar y de educarse sigue siendo en estricto sentido un acto político... y no solo pedagógico"; $; 4$ de hecho, una ilusión de utopía es un acto político de llamar tiempos, espacios y seres en otra dimensión diferente al presente como una forma inteligente y audaz de forjar un mundo posible que no se complazca con lo dado, sino que se atreva a lo inédito. Por tanto, un profesor comprometido con su artesanía del devenir convoca la utopía de lo posible dentro de lo imposible, solo así dará vida al profesor devenido, perseguido y requerido. Entonces para no seguir desfasados, envueltos en cantos de sirena y confundidos en la promesa, se espera que el profesor no dilapide el poco control que aún le queda en la educación, sin delegar ni delegarse para que no termine de regreso a las cavernas llorando frente de sus propias sombras, con ello, confrontará a un ser humano despersonalizado que podría finalizar amando aquello que lo destruye, aquello que lo encadena.

13 Guarín Jurado, Germán, Razones para la racionalidad en horizonte de complejidad, (Manizales: Editorial Universidad de Manizales, 2004), 37.

14 Freire, Paulo, Pedagogía de la esperanza. (Rio de Janeiro: Siglo Veintiuno Editores, 1992), 17. 
El acto de aula con preguntas momias genera respuestas disecadas, respuestas cadáver, procesos que desmotivan, la cual nos quiere mostrar González "La inutilidad o impertinencia de muchas enseñanzas y la despersonalización del acto de aula conllevan al desinterés del estudiantado por el aprendizaje", ${ }^{15}$ es evidente que con estas formas de comprenderse en el ejercicio académico un profesor no es artesano de su devenir ni deja intuir algunas fantasías de utopía; es un docente con miradas estrábicas, con miradas perdidas, un profesor sin miradas.

\section{Las miradas del docente}

El docente debería afinar las miradas. A veces, parece que algunas enfermedades visuales se trasladaron al ejercicio del profesorado, estrabismo o desviación de la mirada; presbicia o vista cansada; astigmatismo o vista confusa e incompleta; miopía o vista corta para lo lejano; hipermetropía o vista débil para lo cercano; daltonismo o vista que confunde los colores; cataratas u ojo con velos y ambliopía u ojo perezoso, todos estos son síntomas de un mal mayor: ceguera consentida, el que sabe hacerse de la vista gorda.

La irracionalidad como acto demencial de aula sería una mirada para evitar, para no caer en ella, ya en el texto La caída del angelus novus de Santos expone que "La irracionalidad de la sociedad moderna reside en que dicha sociedad ha sido producto de una voluntad particular, la del capitalismo, y no de una voluntad general, en palabras de Horkheimer, una voluntad mancomunada y consciente de sí misma". ${ }^{16}$ Es sí una labor o un panorama del docente ser consciente y hacer consciente al estudiante para no ser producto de la voluntad del capitalismo, de las voluntades que nos quieren decir cuál es el camino a seguir, que se constituyó en una especie de enfermedad social mayor: el dejarse guiar por los demás

Es posible que muchos profesores padezcan varias enfermedades visuales cuando no todas a la vez. Para lo cual, los docentes precisan identificar

15 González González, Miguel Alberto, Umbrales de indolencia. Educación sombría y justicia indiferente. (Manizales: Universidad de Manizales, 2010), 46.

16 Santos, Boaventura. De la mano de Alicia (Bogotá: Ediciones Uniandes, 1998), 27. 
cuáles son sus problemas visuales que no le permiten ver el pasado, observar el presente y visualizar el futuro de los territorios, de los tiempos, de la humanidad.

El docente no puede ser totalitarista ni absolutista, en el libro Del poder y otros ensayos Gutiérrez escribe que "Quien desarrolla una mentalidad totalitaria, en el fondo, busca seguridad sicológica. Un sistema de valores, político, partidario, religioso, etc., con el cual se identifique la verdad" ${ }^{17}$ Esa búsqueda de su propio sistema de valores, de sus propios dogmas para después imponerlos no debe ser el panorama de ningún profesor, un tiempo totalizado e impuesto desvirtúa el acto enseñante de cualquier docente.

En la idea de cambio constante, donde nada es eterno, ni el cielo o el infierno, ni el ser que promovió Parménides, es donde el profesor que se sabe un artesano de su devenir, no se conforma con lo dado porque hace de sus fantasías una utopía, aun sabiendo que nada permanecerá para siempre, de hecho ya nos lo había advertido Heráclito "No se puede sumergir dos veces en el mismo río. Las cosas se dispersan y se reúnen de nuevo, se aproximan y se alejan". ${ }^{18}$ Nada permanece, solo el tiempo historizado, en crónicas de humanidad, algunas de ellas insignificantes por su valor de pertinencia. No obstante, un docente no puede conformarse con los avances de tantas insignificancias que terminan por ser mitologías que no sabemos cómo confrontar. Una de las grandes insignificancias sería la indigencia social por los lenguajes, desde el aula se ha permitido cierta indigencia para avanzar por los lenguajes, las palabras llegan y se van sin ser comprendidas o revisadas, es decir, palabras que nos piensan, nos piensan desde el afuera, desde el afuera nos dicen qué hacer y cómo hacerlo en una arremetida al tiempo vital del mismo docente, de la humanidad misma. De ahí la vitalidad de un profesor que se atreva a: ${ }^{19}$

17 Gutiérrez Millán, Alfonso. Del poder y otros ensayos (Pereira: Gráficas Olímpica, 1994), 7.

18 Heráclito, Fragmentos (Barcelona: Ediciones Folio, S. A, 2007), 52.

$19\left(^{*}\right)$ González González, Miguel Alberto. Figura ;. Un profesor se atreve. Manizales: Universidad de Manziales 2013. 
Figura 1. Un profesor que se atreve.

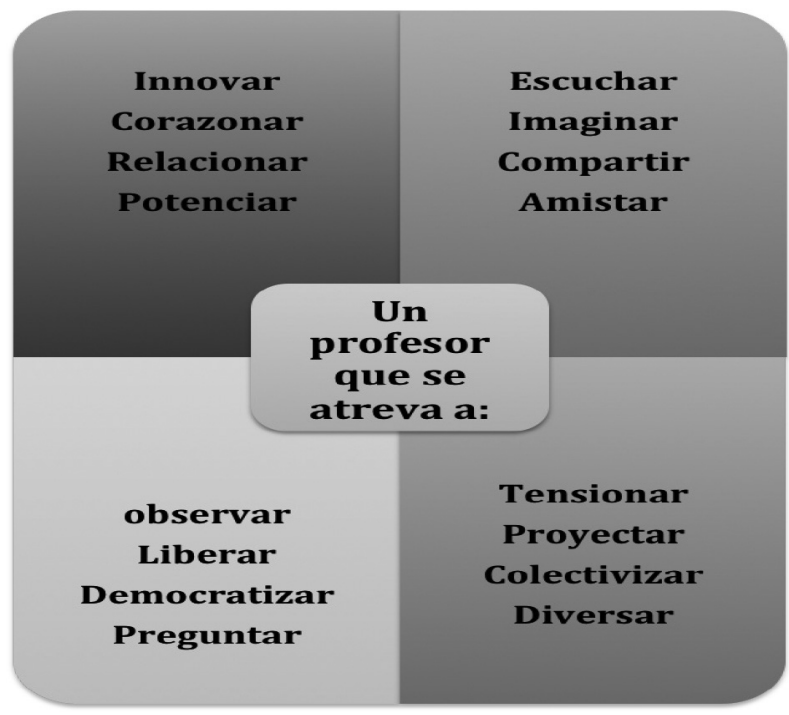

Fuente: Elaboración propia, 2013.

Se desprende desde las voces, desde las esperanzas, desde las necesidades mismas, desde los tiempos que nos corresponden a un profesor que vaya más allá de su rol, un profesor comprometido como nos muestra el gráfico. Un profesor que se atreva a creer que es posible desde lo imposible, porque de lo sabido, de lo dado, sabemos demasiado. Ese tiempo, es un tiempo de ilusiones, de utopías es lo que nos sugieren los profesores entrevistados.

\section{El tiempo del docente. ¿Ilusiones de una utopía?}

Desde la dictadura del lenguaje, ni todo se elucida ni tampoco se le entrevé solución a todo, en unos sucesos que requieren ser leídos para que la esperanza no se convierta en otra forma de alienación. El tiempo del docente requiere ser flexible, el docente no puede entenderse al servicio de una institución y no verse como su vasallo, sino al servicio de la humanidad porque, sin dudas, precisamos de Seres Humanos que decidan potenciar el pasado y que no se dejen perturbar con un presente acorralador, un presente que niega los tiempos transcurridos y, a ojos vistos, pretende dar cuenta de lo venidero en una alienación temporal que no hemos leído con suficiencia. 
La verdadera educación requiere a un maestro que supere los ídolos expuestos por Bacon en su libro el Novum organum, en los ídolos de la mente que bloquean la inteligencia; los idola tribus o de la especie, los idola specus o ídolos de la caverna; los idola fori o ídolos del mercado; los idola theatri o ídolos del teatro, todos estos ídolos se deben identificar no solo para el proceso científico sino para el proceso enseñanza-aprendizaje; ya sabemos que los ídolos someten, cuando no, entontecen a la humanidad.

Si el docente no sabe luchar contra estos muros, si no los intuye, siempre seguirá repitiéndose en sus yerros, no logrará resolver los engaños. Entiéndase que las instituciones hacen uso de esos ídolos unas veces adrede, en otras en pleno desconocimiento. No obstante, en administración se sabe que muy pocas decisiones se emprenden en desconocimientos, es decir, el uso acertado e intencionado de los ídolos les puede asegurar un presente halagüeño, pero les conduce a un futuro devastador. La educación sincerada requiere del maestro que logre enfrentar a la autoridad que ofrecen los ídolos; tal decisión no es cuestión de caprichos, es una urgencia lingüística-intelectual-factual, pues no es suficiente descubrir-describirlos, es indispensable superarlos. Esta resolución sólo solo es posible en hombres que entiendan su labor en debilitar muros, incluso los propios que son los más influyentes.

El maestro en autocolocación de espacio y tiempo hará labores de pensador, como sugiere Foucault al decirnos que el trabajo de un intelectual no consiste en moldear la voluntad política de los demás, sino en interrogar las evidencias y los postulados, sacudir los hábitos adquiridos, las maneras de actuar, de pensar y, por tanto, disipar las familiaridades adquiridas.

El maestro tiene un compromiso consigo y con la sociedad, un compromiso es una promesa con un enviar nuestras intenciones al futuro, un lanzar adelante nuestros deseos en relación con los tiempos, los espacios, el otro, los otros, los alguienes, los ningunos y los cualquieras, es un arrojarnos en lenguajes que nos implican en la donosura del saber que somos proyectos y jamás, casi en una ética kantiana, proyectiles.

En cierto modo, el ser humano que no domine el espacio y tiempo, que no se interese por los suejetos o que, sumido en la retórica, simula conocerlos, estará en condiciones de inferioridad para enfrentar el mundo. Schopenhauer refiere que nuestro mundo civilizado no es más que una mascarada 
donde se encuentran caballeros-curas-soldados-doctores-abogados-sacerdotes-filósofos, pero no son lo que representan, sino solo la máscara bajo la cual, por regla general, se esconden especuladores de dinero, de oficio. Por tanto, nos insiste el maestro "Todo lo que de alguna manera pertenece o puede pertenecer al mundo está inevitablemente condicionado por el sujeto y existe para el sujeto. El mundo es una representación". ${ }^{20}$

Si el mundo es una representación, entonces el profesor en la autocolocación requiere asumir postura con responsabilidad histórica, en su instalación en la realidad para debilitar los muros de la educación, en instancias de apropiación de una subjetividad en camino a una pluralidad constitutiva que en el día a día impulse espacios para aventurar prognosis.

De vuelta a Sábato, es curioso y casi catastrófico cuando dice "A veces le prestan un cuidado a las mascotas artificiales como si vivieran; en cambio personas en estado de abandono y animales en extinción, que sí necesitan afecto no lo reciben"; mascotas naturales y electrónicas que nos hacen olvidar del hombre. Una buena escuela es aquella en la que además de enseñarse contenidos teóricos se promueven las categorías necesarias para el desarrollo humano. Así las cosas, al profesor le queda mucho por resolver si quiere sumergirse en experiencias vitales de amor-solidaridadresponsabilidad.

Esa responsabilidad exige estar en el momento, en el aquí y en el ahora, como expone González "La expresión latina carpe diem, designa aprovechar el día, si ello es posible ¿cómo podremos aprovechar el día para no perder los años? Esos siguen siendo caminos de prueba, de ensayo-error. ¿Cómo aprovechar la oscuridad para encontrar la luz? Sabemos que dentro de un extremo dormita el otro"; ${ }^{\prime 2}$ es posible que perdamos libertad cuando un profesor decide no ser artesano de su devenir, ni, mucho menos, le apuesta a las fantasías de una utopía.

Conocimiento, libertad de pensamiento y felicidad, pueden ir de la mano, pero en articulaciones, mas no en dislocaciones; no se concibe mirar el saber con amargura sino con el gusto del sabor, del deleite. En cuanto al Ser Humano refiere Fromm que "Aun cuando la libertad le ha proporcionado

20 Schopenhauer, Arthur, Schopenhauer en sus páginas (México: Fondo de Cultura Económica, 1991), 45.

21 González González, Miguel Alberto, Horizontes Humanos: Límites y paisajes (Manizales: Universidad de Manizales, 2010 ), 141. 
la independencia y racionalidad, lo ha aislado y por lo tanto, lo ha tornado ansioso e impotente. Tal aislamiento le resulta insoportable, y la alternativa que se le ofrece es de rehuir la responsabilidad de esta libertad positiva, la cual se funda en la unicidad e individualidad del hombre",22 esto es que el profesor con ilusiones de utopía, el profesor que es artesano de su destino no puede rehuir a la libertad, ni sentirle miedo, al contrario, debe comprenderla como su panorama de provocaciones, pues si esto no sucede dejó de ser un artesano para convertirse en un esclavo, es un simple trabajador, un asalariado.

El profesor en su postura y autocolocación no puede sentirse como trabajador, ha de comprenderse en su labor intelectual, de no serlo, debe acatar a Borges, cuando escribió: es fama entre los etíopes que los monos, deliberadamente, no hablan para que no los obliguen a trabajar. Este célebre argentino sentenció que morir es una costumbre que sabe tener la gente. De lo cual se podría agregar que el humano aprende algo y no lo olvida; hubo un primer hombre al que le dio por morirse, entonces a los demás se les ocurrió imitarlo y desde eso no hemos perdido la costumbre de morirnos. ¿Será el docente otro imitador?

Para reconocer a muchos profesores, a veces basta con asistir a una clase de conducción, primero abordan alguna teoría, luego muestran las partes del vehículo, pedales, cambios, dirección y otros elementos de mando. A la hora de hacer la práctica el instructor insiste en que el aprendiz domine el freno; acaso ¿Lo fundamental es frenar? ¿Qué pasa con la conducción, con el avanzar? Se reprime la posibilidad de ir al frente, a tomar riesgos. No faltará el que argumente que, insistiendo en los frenos, se previenen accidentes, -la práctica nos muestra cientos de accidentes trágicos de los que aprendieron a frenar.

Un docente que aplaca o reprime fomenta seres de poca ambición para aventurar los cambios, es el perfecto para los propósitos de los poderes, no hay un poder absoluto, existen poderes y eso no se puede desconocer. Un maestro no puede estar al servicio del poder político, económico o religioso que impera en el momento, si lo hace, siempre enseñará a frenar, a acatar el orden establecido, a respetar las normas y disposiciones del poder dominante,

22 Fromm, Eric, Miedo a la libertad (Buenos Aires: Editorial Paidós, 2005), 24. 
por tanto, el discurso de este maestro no tomará vuelo, será esclavo de su mediocridad y objeto de quincalla por su poca perspectiva en convocar la alegría del desafío.

La esperanza, aliada del futuro, nos indica que la felicidad está en el horizonte; es el individuo, que volviéndose sujeto desatado, evade sus máscaras de actor para que las relaciones temporales instante-efímeroeterno no lo convoquen a otra alienación, entendiendo que la felicidad reside con el hombre, no con el tiempo; hay cierta crueldad en esto.

Pero de la crueldad también se requiere una mirada del docente de la que nos advierte Derrida al indicarnos que "Podemos detener la crueldad sangrienta (cruor, crudus, crudelitas), podemos poner fin al asesinato con arma blanca, con guillotina, en los teatros clásicos o modernos de la guerra sangrienta, pero según Nietzsche o Freud, una crueldad psíquica los suplirá siempre inventando nuevos recursos. Una crueldad psíquica seguiría siendo desde luego una crueldad de la psyché, un estado del alma, por lo tanto, de lo vivo, pero una crueldad no sangrienta". ${ }^{23}$ Es como si en la crueldad se diese paso a la pérdida de cierta felicidad y como si la crueldad fuese una soberana de la humanidad.

La felicidad está perdida en el futuro, esa angustia no puede conducir a un pesimismo ilustrado, sino a un presente potencial en optimismo. Una profesión de fe como lo sugiere Derrida, de un profesor que haría como si les pidiese a ustedes permiso para ser infiel o traidor a sus costumbres es el que se requiere para pensar la felicidad con la generosidad de la búsqueda, no con las precariedades con que nos la venden en la economía o en muchas de las religiones conocidas.

Para que el maestro de carne-huesos-sueños y caprichos no sufra una desaparición forzada, ni sea reemplazado por un ordenador, un manual, un chip, una píldora o simplemente quede en la historia de los museos, deberá hacer prognosis, adelantarse a los acontecimientos, a sus miedos, ser prometeico, ser un eslabón.

23 Derida, Jacques, Estados de ánimo del psicoanálisis. Lo imposible más allá de la soberana crueldad (Santiago de Chile: Universidad de ARCIS, Edición Electrónica, 2000), 5. 
Si es cierto que un sistema es tan fuerte, como fuerte sea el elemento o eslabón más débil, algunas preguntas nos acompañan esta idea ¿cuál es el elemento más débil de la educación? ¿En esa cadena en qué posición queda el maestro? El maestro deberá leer los cambios sociales y permanecer expectante para entregar alternativas de vida y subsistencia. Le corresponde resolver los conflictos por medio del diálogo, ahuyentando el autoritarismo, en donde el norte ya no lo sigue siendo y el sur no se ha ocupado de sus propias miradas, de sus perspectivas. ¿Cuál es el sur de los pensamientos?, ¿dónde queda el sur de los deseos? Estos cuestionamientos surgen en el mismo momento en que se deslocaliza la visión y se desparadigmatiza el cerebro para permitirle regresar a su elaboración de fantasías; para ello estamos urgidos de maestros atrevidos, renovadores-renovados en sus discursos, que no le apuestan a realidades únicas.

Es indudable que la realidad es cambiante para todos, de ello Zemelman nos alerta al decir "La realidad que enfrentamos, la realidad socio-histórica, tiene múltiples significados. No es una realidad clara, inequívoca, con una significación cristalina y a la que se pueda abordar sencillamente construyendo teorías" ${ }^{24}$ Es decir, no es suficiente con apreciar la teoría o la práctica por sí solos como un norte, ambas son una posibilidad para leer el mundo, un mundo que cambia y, claro, la teoría, junto a la práctica, si no son actualizadas pasan a ser meros fósiles; ni siquiera pensables como probables nortes o sures.

Ya sin nortes, ¿cuál será el sur de los miedos? Sin duda, los más caóticos son los miedos. ¿Dónde queda el sur de las desgracias o angustias? Ojalá no se busquen los nortes donde las respuestas van siendo escasas y fosilizadas. ¿Hay sur en la promesa? No olvidemos que en toda promesa hay algo de inmortal y, mientras no se cumpla, seguirá siendo promesa. ¿Existe sur en la pasión? Cierto es que en el odio se expresan todos los puntos cardinales. ¿Se antepone el sur de la verdad al sur de la mentira? Es probable que en algunos lugares se alternen. ¿El sur de la educación, del infierno, del cielo, del egoísmo, de la maldad, de la pereza y de la torpeza ya fue indagado? Pensarlos puede romper las barreras, los límites

24 Zemelman, Hugo, Voluntad de conocer. (Barcelona: Editorial Anthropos, 2005), 63. 
mismos del lenguaje. ¿Si no es el norte, ni el centro, ni los laterales, ni el sur del conocimiento lo que se expresa, a qué juegan los docentes?

La prudencia siempre aconseja rendirse. ¿Qué pasará si el maestro decide no esperar los llamados de la prudencia y opta por abrir las alas fraguando el sueño de ser libre? Será, por irregular que parezca la respuesta, un provocador de su destino, un artesano y, por tanto, del destino de otros seres con quienes recorre o recorrerá su vida serán posibles ilusiones de una utopía. Un docente está comprometido a seguir promoviendo pensamiento y movimientos sociales de base, a constituir proyectos colectivos, a ser proyecto no individual sino comunal, a corazonar las apuestas imposibles porque de lo posible sabemos demasiado, a saber que siempre es dable creer y accionar realidades para la humanidad que deseamos y cuando algo no vaya adecuado, en los azares de prometeos andinos e inmensidades de caminos toltecas, se hará lo que Heráclito escribió, salir en la oscuridad a encender una luz para sí, después de esto requiere complejizar al máximo lo mínimo observado para que de la mano de otros, estudiantes-compañeros y comunidad, encender una constelación de luces para la humanidad, en un mandar obedeciendo como practican los zapotecas.

CODA: En el libro Modernidad líquida, indica Zygmunt Bauman: "lo pequeño, lo liviano, lo más portable significa ahora mejoría y progreso". Esperemos que este polaco se refiera a cualquier cosa, menos a profesores nanotecnólogos que, creyendo en el norte de los acontecimientos como algo inexorable, sigamos apequeñando las ideas e incluso decidamos, no solo ver todo como líquido sino en estado gaseoso, en vapores inalcanzables como muchas ideas de aula que rondan las academias de estos tiempos.

No basta pensar, señala Unamuno, hay que sentir nuestro destino. Claro está que no es padecerlo, sino enfrentarlo como hombre erguido, insertándose en el tiempo para construir un lugar en el espacio, habitarlo en su rol de maestro y erigir un compromiso educativo, de alegre circulación, para el devenir de la humanidad, evitando ser animales cansados de cargar recuerdos inútiles o dolores eternos. 
El hombre es hecho por otros, fabricado por otros, si se quiere, deviene producto cultural heterónomo, por tanto, aprender a conquistar la autonomía, liberarse de las cadenas de la cultura es una misión de la educación devenida que ningún docente debería delegar si es que le queda alguna dignidad, si es que se cree artesano y con ilusiones de utopía.

El hombre, pues, acabamos de verlo, es hecho por otros.

Philippe Meirieu.

\section{FUENTES}

Bauman, Zygmunt. Modernidad líquida. Buenos Aires: Fondo Cultura Económica, 2006.

Derrida, Jacques. Estados de ánimo del psicoanálisis. Lo imposible más allá de la soberana crueldad. Santiago de Chile: Universidad de ARCIS, Edición Electrónica, 2000.

Foucault, Michael. "Vérité et pouvoir", Revista L'Arc, No. 70 (1977): 16-23.

Foucault, Michael. Estrategias de poder. Barcelona: Paidós, 1999.

Freire, Paulo. Pedagogía de la esperanza. Rio de Janeiro: Siglo Veintiuno Editores, 1992.

Freire, Paulo. Pedagogía del oprimido. (Montevideo: Tierra Nueva., 1970), .Consulta 16 de agosto de 2012. http: / / www.libroselectrónicosgratis.com

Fromm, Erich, Miedo a la libertad. Buenos Aires: Editorial Paidós, 2005.

Gadamer, Hans-Georg. La herencia de Europa. Barcelona: Ediciones península, 1990.

Ghiso, Alfredo. Potenciando la diversidad. Diálogo de saberes, una práctica hermenéutica colectiva. Medellín: Centro de Investigaciones Fundación Universitaria Luis Amigó, 2000. Consulta 15 de junio de 2011. http:/ / bibliotecadigital.conevyt.org.mx/colecciones/documentos/potenciando_diversidad.pdf

Goethe, Johan. Fausto. Barcelona: Bruguera, 1975.

González González, Miguel Alberto, Horizontes Humanos: Limites y paisajes. Manizales: Universidad de Manizales, 2010.

González González, Miguel Alberto, Umbrales de indolencia. Educación sombría y justicia indiferente. Manizales: Universidad de Manizales, 2010.

González González, Miguel Alberto. Gráfico. Un profesor se atreve a. Manizales: Universidad de Manizales, 2013. 
Guarín Jurado, Germán. Razones para la racionalidad en horizonte de complejidad. Manizales: Editorial Universidad de Manizales, 2004.

Gutiérrez Millán, Alfonso. Del poder y otros ensayos. Pereira: Gráficas Olímpica, 1994.

Heráclito, Fragmentos, Barcelona: Ediciones Folio, S. A, 2007.

Meirieu, Philippe. Frankenstein educador. Barcelona: Leartes Ediciones, 1998.

Quintero Valencia, Enrique. Cuentos de un Máximo Gris. Manizales: Editorial Manigraf, 1998.

Santos, Boaventura. De la mano de Alicia. Bogotá: Ediciones Uniandes, 1998.

Schopenhauer, Arthur. Schopenhauer en sus páginas. México: Fondo de Cultura Económica, 1991.

Zemelman, Hugo, Los horizontes de la razón III. El orden del movimiento. Barcelona: Anthropos, 2011.

Zemelman, Hugo. (2005). Voluntad de conocer. Barcelona: Editorial Anthropos, 2005.

Zuleta, Estanislao. Educación y democracia. Un campo de combate. Bogotá: Editorial corporación tercer milenio, 2011.

\section{REFERENCIAS}

Borges, Jorge Luís. Nueva antología personal. Buenos Aires: Ediciones Bruguera, 1980.

Chomsky, Noam. La geopolitica del Plan Colombia. Bogotá: Ediciones izquierda viva, 2003.

Chomsky, Noam. Una nueva generación dicta las reglas. Barcelona: Editorial Crítica, 2002.

Clark, Karen Rose Jandreau. A pedagogy for justice: Reinterpreting democracy, normative whiteness and the public space. Pennsylvania: University of Pennsylvania, 2004.

Cortes Pena, Patricia. La transformación de la universidad de cara al siglo XXI: Estudio de caso de una universidad mexicana. Montreal: Universite de Montreal, 2000.

Cortina, Adela. Hasta un pueblo de demonios: Ética pública y sociedad. Madrid: Ediciones Tauro pensamientos, 1998.

Gil Montoya, Rigoberto. La urbanidad de las especies. Pereira: Fondo Editorial Risaralda, 1996.

González González, Miguel Alberto. Analectas de la caverna. Pereira: Editorial Papiro, 2004.

González González, Miguel Alberto. Horizontes de la praxis didáctica. Manizales: Universidad de Manizales, 2008.

González González, Miguel Alberto. Visión de filósofos y literatos sobre el devenir de la universidad. Manizales: Universidad de Manizales, 2006. 
Habermas. Jurgen. Teoría y praxis. Barcelona: Editora Altaya, 1995.

Ingenieros, José. El hombre mediocre. Bogotá: Editorial Oveja Negra, 2001.

Kahneman, Daniel. Pensar rápido, pensar despacio. Barcelona: Random House Mondadori, 2012.

Melich, Joan Carles. La ausencia de testimonio. Ética y pedagogía en los relatos del holocausto. Barcelona: Anthropos, 2001.

Morin, Edgar. El método. La naturaleza de la naturaleza. Madrid: Ediciones Cátedra, 2001.

Morin, Edgar. Introducción al pensamiento complejo. Barcelona: Editorial Gedisa, 2001.

Morin, Edgar. Los siete saberes necesarios para la educación del futuro. Bogotá: Imprenta nacional de Colombia, 2000.

Ospina, William. La escuela de la noche. Bogotá, Editorial Norma, 2008.

Parménides, Poema, Barcelona: Ediciones Folio, S. A, 2007.

Rivera Piragauta, José Alberto. "La educación, entre la ciencia y la técnica". Revista Historia de la Educación Latinoamericana. Vol. 14, No. 19, (2012).

Sábato, Ernesto. La resistencia. Bogotá: Editorial Planeta, 2000.

Sánchez Fajardo Silvio. Diálogos imperfectos. Pasto: Ediciones universidad de Nariño, 2004.

Skliar Carlos. No tienen prisa las palabras. Buenos Aires: Editorial Candaya, 2012.

Vigotsky, Semenovich. Pensamiento y lenguaje. Ciudad de la Habana: Editorial Pueblo y Educación, 1992.

Zemelman, Hugo. Necesidad de conciencia. Barcelona: Editorial Anthropos, 2002.

Zemelman, Hugo. Sujeto: existencia y potencia. Barcelona: Editorial Anthropos, 1998.

Zemelman, Hugo. El ángel de la historia. Determinación y autonomía de la condición humana. Barcelona: Anthropos, 2007.

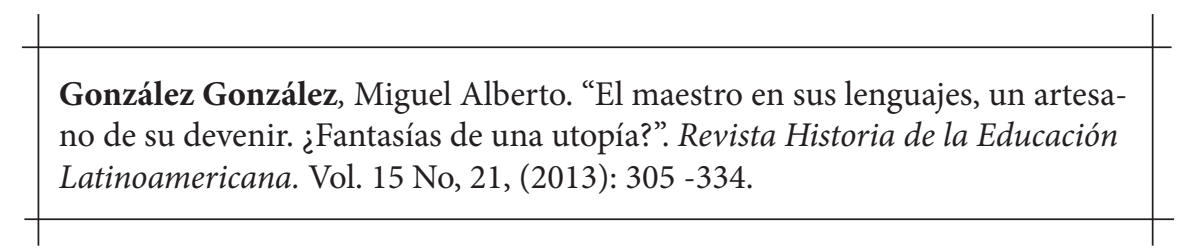

